\title{
MODELING OF THE REBAR PRODUCTS RECYCLING TECHNOLOGY BY RADIAL-SHEAR ROLLING AND DRAWING
}

\author{
${ }^{1}$ Sergey LEZHNEV, ${ }^{1}$ Abdrakhman NAIZABEKOV, ${ }^{2}$ Dmirty KUIS, ${ }^{2}$ Andrey KASPEROVICH, \\ ${ }^{3}$ Evgeniy PANIN \\ ${ }^{1}$ Rudny Industrial Institute, Rudny, Kazakhstan, sergey legnev@mail.ru, kgiu@mail.ru \\ 2Belarusian State Technological University, Minsk, Belarus, KuisDV@belstu.by, andkasp@belstu.by \\ ${ }^{3}$ Karaganda Industrial University, Temirtau, Kazakhstan, cooper802@gmail.com
}

\section{https://doi.org/10.37904/metal.2021.4108}

\begin{abstract}
The paper presents the results of computer modeling of a new technology for bar scrap recycling, which includes two processing technologies: radial-shear rolling and drawing. At the first stage, the initial billet in the form of a reinforcement profile with a diameter of $16 \mathrm{~mm}$ is heated to $1000{ }^{\circ} \mathrm{C}$ and rolled on a radial-shear rolling mill to a diameter of $14 \mathrm{~mm}$. The purpose of this stage is to remove the reinforcement ribs, both longitudinal and transverse. At the second stage, the billet is cooled to $800{ }^{\circ} \mathrm{C}$ and rolled on a radial-shear rolling mill from a diameter of $14 \mathrm{~mm}$ to $10 \mathrm{~mm}$ in 2-4 passes, depending on the technological capabilities of the mill. The goal of this stage is to implement severe plastic deformation in the metal of the deformable billet in order to obtain a gradient ultrafine-grained structure in it. At the third stage, the rolled billet is cooled to $20{ }^{\circ} \mathrm{C}$ and drawn from a diameter of $10 \mathrm{~mm}$ to a diameter of $8 \mathrm{~mm}$ in 2 passes. The purpose of this stage is to align the helical surface obtained after radial-shear rolling, and to obtain a high-quality commercial product in the form of a bar (wire) of circular cross-section with a gradient ultrafine-grained structure along the cross-section.
\end{abstract}

Keywords: Recycling, rebar products, radial-shear rolling, drawing, modeling

\section{INTRODUCTION}

Recycling of waste, both ferrous and non-ferrous metals (scrap metal), is a useful process for the economy of any country. This is due to both economic aspects (waste recycling has a positive effect on the extraction of natural resources, as the need for them decreases), and environmental aspects (most modern metal products contain a large number of other chemical elements, many of which are toxic).

One of the most well-known and widespread methods of ferrous metal scrap processing is its remelting and further secondary use. Recently, a fairly new method of metal products processing that have failed or have already served their term, having a circular cross-section, is gaining popularity - deformation in the hot state on radial-shear rolling mills [1-2]. It has already been proved that radial-shear rolling [3] makes it possible to obtain high-quality bars from various materials with a gradient ultra-disperse structure [4-5]. This method is the most technologically advanced and easy to implement in comparison with many other of metal forming methods, which allows for the implementation of severe plastic deformations in the entire deformable body.

It was proposed to use the technology of radial-shear rolling together with the technology of drawing for the processing of conventional bar scrap of ferrous metals, including reinforcing profiles, in order to obtain a highquality commercial product in the form of round cross-section bars or wire. This technological solution is justified by the fact that at present, specialized enterprises for the reception, storage and processing of scrap (waste) of ferrous metals have a large amount of black scrap, which can be processed at the radial-shear rolling mill and drawing mill in order to obtain high-quality bars or wire with a given level of mechanical properties. 
The purpose of these studies is computer modeling and theoretical study of the process of processing (recycling) of ferrous metal bar scrap in the form of a reinforcing profile into a finished commodity product in the form of a bar (wire) of a circular cross-section.

\section{COMPUTER SIMULATION}

For computer simulation, the Deform program (SFTC, USA) was selected, which allows to simulate metal forming processes of any complexity. The simulation is carried out by the finite element method (FEM). To create a basic model of radial-shear rolling, it was decided to use the parameters of the existing SVP-08 radial-shear rolling mill installed at Rudny Industrial Institute (Rudny, Kazakhstan). The initial billet in the form of a reinforcement profile had a diameter of $16 \mathrm{~mm}$ and a length of $100 \mathrm{~mm}$.

The following route deformation technology was developed:

- The initial billet is heated to $1000{ }^{\circ} \mathrm{C}$, then rolled on a radial-shear rolling mill with a diameter of $16 \mathrm{~mm}$ to $14 \mathrm{~mm}$. The purpose of this step is to remove the reinforcement ribs, both longitudinal and transverse;

- The resulting billet is cooled to $800^{\circ} \mathrm{C}$, then rolled on a radial-shear rolling mill from a diameter of $14 \mathrm{~mm}$ to $10 \mathrm{~mm}$ in several passes. The goal of this stage is to implement severe plastic deformation in the metal of the deformable billet in order to obtain a gradient ultrafine-grained structure;

- Cooling of the rolled billet to $20^{\circ} \mathrm{C}$ and subsequent drawing from a diameter of $10 \mathrm{~mm}$ to a diameter of $8 \mathrm{~mm}$ in 2 passes. The purpose of this stage is to align the helical surface obtained after radial-shear rolling and give the billet a marketable appearance.

DIN BSt420S steel was chosen as material of the billet, which is the closest analogue of 25G2S reinforcing steel. Two-stage heating for radial-shear rolling was chosen for the following reasons. At the first stage, when it is necessary to remove the reinforcing ribs, it is advisable to heat the workpiece more strongly to ensure greater ductility of the metal. At the second stage, when the purpose of rolling is intensive grinding of grains, it is advisable to reduce the temperature to the level of the beginning of recrystallization.

The speed of rotation of the rolls was equal to $50 \mathrm{rpm}$, as the nominal value on the SVP-08 radial-shear rolling mill. The friction coefficient at the contact of the workpiece and the rolls was assumed to be 0.7 , as the recommended value for hot rolling in Deform, the Siebel type of friction was set. This type of friction is recommended for processes where the contact pressure is higher than the yield strength (a characteristic condition for processes of severe plastic deformation). During drawing, the friction coefficient at the contact of the workpiece and the drawing tool was assumed to be 0.15 , which corresponds to the polished surface of the drawing with the use of grease. The mechanical and thermal problems were solved simultaneously by setting a non-isothermal type of calculation. At the same time, the following heat transfer coefficients were set for the billet: with the environment $=50 \mathrm{~W} /\left(\mathrm{m}^{2} \cdot \mathrm{K}\right)$; with deforming tools $=5000 \mathrm{~W} /\left(\mathrm{m}^{2} \cdot \mathrm{K}\right)$.

To create the geometry of the rolls, the KOMPAS-3D solid-state modeling program was used, while preserving the finished geometry in the STL format. When rolling, the rolls and the drawing tool were taken by rigid bodies, and the material of the workpiece was elastic-plastic. When creating a grid of finite elements on the blank, the relative construction type was chosen - the range of edge lengths of $0.4-0.8 \mathrm{~mm}$ was set.

\section{RESULTS AND DISCUSSION}

In the course of computer modeling, the shape change of the workpiece during the implementation of various stages of deformation was studied and the stress-strain state at these stages of deformation was analyzed.

To assess the strain state, the "equivalent strain" criterion was used [6], the value of which depends on the values of the main strains and is determined by the formula: 


$$
\varepsilon_{E Q V}=\frac{\sqrt{2}}{3} \sqrt{\left(\varepsilon_{1}-\varepsilon_{2}\right)^{2}+\left(\varepsilon_{2}-\varepsilon_{3}\right)^{2}+\left(\varepsilon_{3}-\varepsilon_{1}\right)^{2}}
$$

When considering the stress state, the "equivalent stress" criterion was used to estimate the average level of the resulting stresses [6]. This criterion depends on the values of the main stresses and is determined by the formula:

$$
\sigma_{E Q V}=\frac{1}{\sqrt{2}} \sqrt{\left(\sigma_{1}-\sigma_{2}\right)^{2}+\left(\sigma_{2}-\sigma_{3}\right)^{2}+\left(\sigma_{3}-\sigma_{1}\right)^{2}}
$$

For a full assessment of the resulting stresses, the criterion "average hydrostatic pressure" was studied [6], which allows to estimate the magnitude of the stresses taking into account the sign, i.e., to estimate the magnitude of the tensile and compressive stresses. This criterion is derived from the values of the main stresses and is determined by the formula:

$$
\sigma_{A V}=\frac{\sigma_{1}+\sigma_{2}+\sigma_{3}}{3}
$$

Figure 1 shows the successive stages of forming the workpiece during deformation according to the proposed route technology.

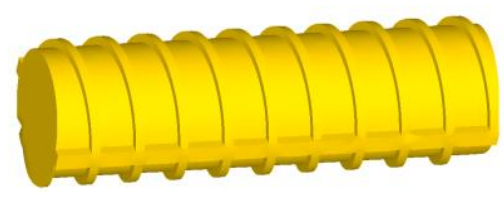

a) The initial billet

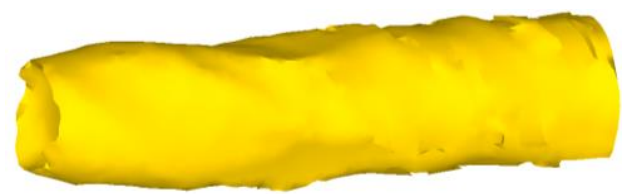

c) The $2^{\text {nd }}$ stage of deformation, after the first compression by $2 \mathrm{~mm}$

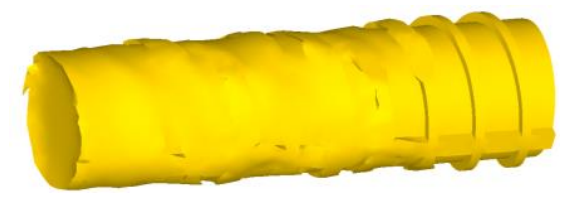

b) The $1^{\text {st }}$ stage of deformation

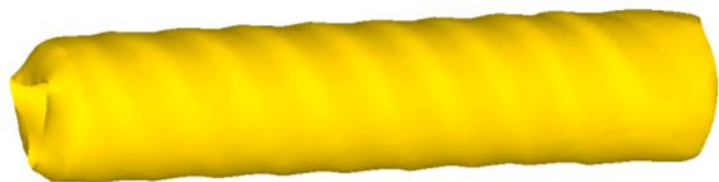

d) The $2^{\text {nd }}$ stage of deformation

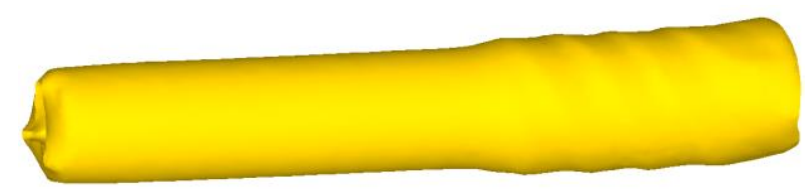

e) The $3^{\text {rd }}$ stage of deformation

Figure 1 Shaping of the workpiece

At the first stage of deformation, the billet in the form of a reinforcement profile receives only a small compression, which removes the longitudinal and transverse ribs (see Figure 1b). Here, due to the compression of only the sections of the location of the edges, the total length of the workpiece practically does not change. In this case, the contour of the section of the workpiece due to the uneven compression in the radial direction takes an irregular shape - irregularities are clearly visible on the surface.

At the next stage, the billet is rolled from a diameter of $14 \mathrm{~mm}$ to $10 \mathrm{~mm}$. At first, it was decided to roll the billet in 2 passes with a compression of $2 \mathrm{~mm}$ in each. As a result, it was revealed that, despite the rolling out of the surface irregularities from the first stage, the overall profile of the workpiece after the first compression by 2 $\mathrm{mm}$ acquires a peculiar helical contour, becoming similar to a drill (see Figure 1c). This is the result of uneven 
compression at the first stage and a sufficiently large compression at the current stage. To reduce the possible effect of screw formation, an attempt was made to reduce the level of single compression to $1 \mathrm{~mm}$ and increase the total number of passes in the second stage to four. As a result, after passing through all four passes of deformation, the workpiece acquired a more regular round shape (see Figure 1d). At the same time, a small helical profile is still observed on the surface, but its level is quite commensurate with the resulting helical line, which is often observed during radial-shear rolling of ordinary round workpieces.

At the last stage, the rolled billet was drawn from a diameter of $10 \mathrm{~mm}$ to a diameter of $8 \mathrm{~mm}$ in 2 passes. After the first drawing cycle, the surface of the workpiece takes on a completely regular round shape (see Figure 1e). Thus, the proposed route technology of deformation allows you to get a rod (wire) of the correct geometric shape from the original reinforcement billet.

When analyzing the equivalent strain, it was decided to consider the longitudinal section of the workpiece, since in this case it is possible not only to numerically estimate the parameter, but also its distribution over the cross-section.

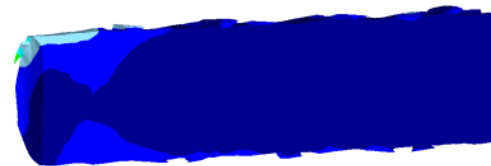

a) After the first stage of deformation

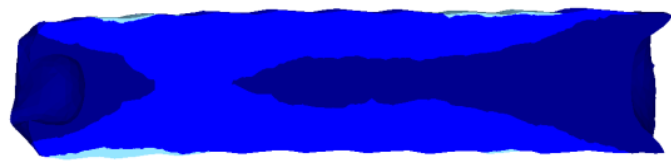

b) After the second stage of deformation

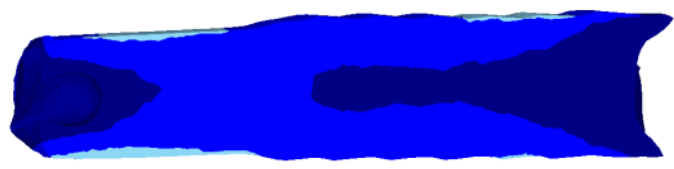

c) After the third stage of deformation

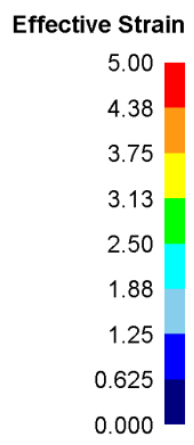

Figure 2 Equivalent strain

At the first stage, the strain develops mainly in the surface layers of the workpiece. The only exception is the front end of the sample, where the strain penetrates deep due to the initial capture of the workpiece by the rolls. The average level of equivalent strain in the first stage is $0.6-0.7$. In the second stage, the workpiece is subjected to four $1 \mathrm{~mm}$ compression. Due to the implementation of such a deformation scheme, the inner zones of the workpiece begin to be processed - the equivalent strain increases throughout the entire crosssection of the workpiece, creating a gradient distribution pattern (from 0.4 in the center to 1.25 on the surface). At the third stage, when drawing, the workpiece also receives an increase in strain in the entire cross-section - in the central zone, the level of equivalent strain reaches 0.6 , gradually increasing to 1.64 on the surface.

When considering the components of the stress state (equivalent stress and average hydrostatic pressure), it was decided to consider them in the cross-section of the workpiece, since, unlike the equivalent strain, these parameters act in the zones of the direct deformation process and are reset when the load is removed.

Considering the equivalent stress at the first stage (see Figure 3a), it can be noted that the maximum values of this parameter develop only on the rebar edges, reaching $250 \mathrm{MPa}$. In the main section of the workpiece, the stress level is reduced to $150-170 \mathrm{MPa}$. Due to the RSR scheme, three separate deformation zones are formed in the cross-section, the depth of penetration deep into the workpiece is not symmetrical, since in any arbitrary cross-section, some rolls will compress the ribs, others will contact the main body of the workpiece.

At the second stage (see Figure $3 b$ ), due to the lack of reinforcement ribs, compression according to the RSR scheme is already carried out over the entire body of the workpiece. As a result, the distribution of all three deformation zones deep into the workpiece becomes more symmetrical. The maximum stress level develops in the areas of metal contact with the rolls and reaches $200 \mathrm{MPa}$. 


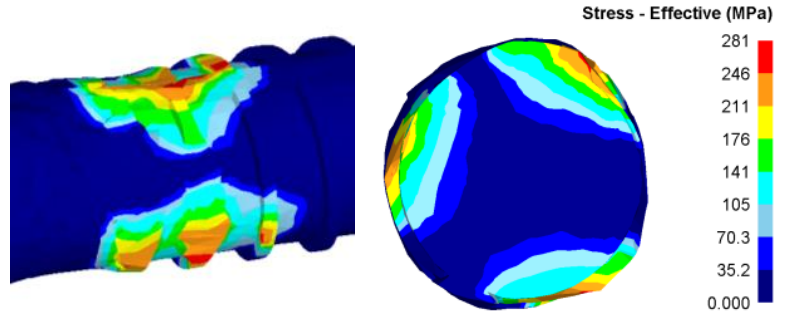

a) After the first stage of deformation
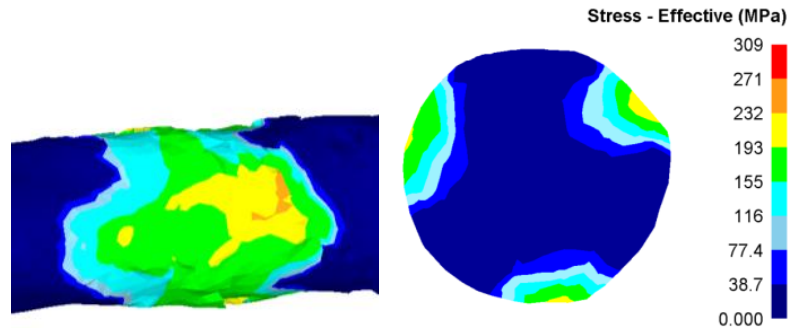

b) After the second stage of deformation

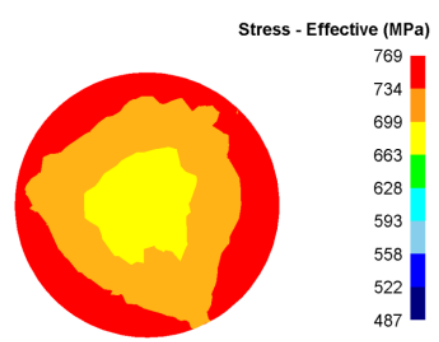

c) After the third stage of deformation

Figure 3 Equivalent stress on the surface and in the section of the workpiece

At the third stage (see Figure 3c), when drawing a rolled billet cooled to ambient temperature, the stress level increases sharply - on the surface, their value reaches $750 \mathrm{MPa}$, gradually decreasing to $680 \mathrm{MPa}$ in the center. When drawing a conventional round billet, the stress distribution pattern is annular. In this case, an annular stress distribution is observed with the effect of superimposing the triangular symmetry of the deformation zones at the previous RSR stage. In other words, the presence of a small helicity (see Figure 1d) leads to a distortion of the annular shape of the focus of deformation during drawing.

When considering the average hydrostatic pressure, it was noted that the distribution of this parameter is largely similar to the distribution of the equivalent stress. So, at the first stage (see Figure 4a), the main development of the average hydrostatic pressure occurs on the reinforcement ribs - here compressive stresses occur, reaching $-420 \mathrm{MPa}$.

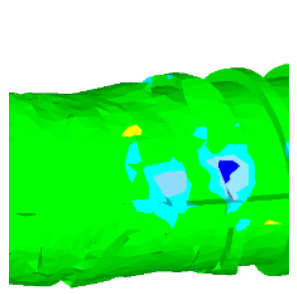

a) After the first stage of deformation
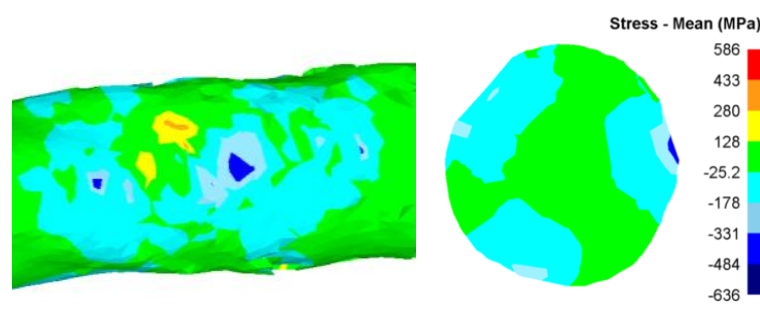

b) After the second stage of deformation
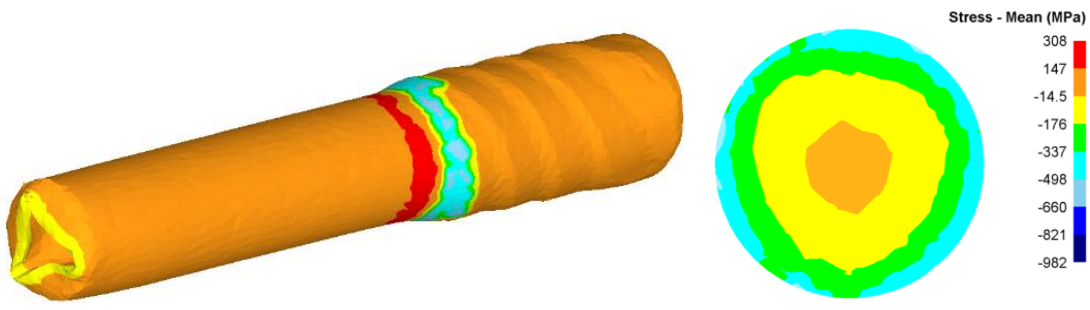

c) After the third stage of deformation

Figure 4 Average hydrostatic pressure on the surface and in the section of the workpiece 
At the same time, in the main body of the workpiece, the level of compressive stresses is much lower, about $180 \mathrm{MPa}$. At the same time, an asymmetric nature of the stress distribution over the cross-section is also observed due to uneven compression along the diameter.

At the second stage (see Figure $\mathbf{4 b}$ ), when the entire body of the workpiece is compressed according to the RSR scheme, the distribution of all three deformation zones deep into the workpiece becomes more intense and symmetrical. The maximum level of compressive stresses develops in the areas of metal contact with the rolls and reaches $-360 \mathrm{MPa}$. In the third stage (see Figure 4c), when drawing the rolled billet at ambient temperature, the stress level increases sharply. At the same time, the distribution of the average hydrostatic pressure changes dramatically - if at the first two stages of radial-shear rolling, the deformation zones mainly consisted of compressive stresses, then at the drawing stage, both compressive and tensile stresses are present in the annular deformation center. In the inclined section of the portage, where compression is carried out along the diameter, compressive stresses act on the surface, their value reaches $-490 \mathrm{MPa}$. When moving deep into the workpiece, their intensity decreases, and in the central zone there are already tensile stresses at the level of $60 \mathrm{MPa}$. In a rectilinear calibration belt, a section of surface tensile stresses reaching $170 \mathrm{MPa}$ occurs on the surface of the workpiece. In the future, after the billet leaves the portage, a uniform field of tensile stresses at the level of $35-40 \mathrm{MPa}$ is created in its entire cross-section due to the pulling action at the front end of the billet.

\section{CONCLUSIONS}

The paper presents the results of computer modeling of a new technology for recycling of bar scrap in the reinforcement profile, which includes two processing technologies: radial-shear rolling and drawing. The results of computer simulation showed that at the first stage of radial-shear rolling at a temperature of $1000^{\circ} \mathrm{C}$, the ribs of the reinforcement profile, both longitudinal and transverse, are rolled out. With the further implementation of the radial-shear rolling process, but already at a temperature of $800{ }^{\circ} \mathrm{C}$, a favorable stressstrain state is created in the deformed metal to obtain bars of circular cross-section with a gradient ultrafinegrained structure. The introduction of such metal forming method as drawing at ambient temperature into the proposed technological scheme of recycling of bar scrap allowed to obtain a rod (wire) of the correct geometric shape with a diameter of $8 \mathrm{~mm}$. If it is necessary to obtain a wire of a smaller diameter, the number of passes can be increased with the introduction of intermediate annealing into the proposed technological scheme of recycling (in order to avoid the appearance of cracks between the drawing passes).

\section{ACKNOWLEDGEMENTS}

\section{This study was funded by the Science committee of the Ministry of education and science of the Republic of Kazakhstan (Grant № AP08955575).}

\section{REFERENCES}

[1] BOGATOV, N.A. Method of repair of pumping rods by plastic deformation. RU Patent 2356718. 2009.

[2] OSACHUK, E.A. Repair of pumping rods on the principle of hot radial-shear screw rolling. Engineering practice 1. 2017, pp. 15-19.

[3] GALKIN, S.P. Radial shear rolling as an optimal technology for lean production. Steel in Translation. 2014, vol. 44, pp. 61-64.

[4] DEREVYAGINA, L.S., GORDIENKO, A.I., POCHIVALOV, Y.I., SMIRNOVA, A.S. Modification of the Structure of Low-Carbon Pipe Steel by Helical Rolling, and the Increase in Its Strength and Cold Resistance. Physics of Metals and Metallography. 2018, vol. 119, pp. 83-91.

[5] BAJOR, T., KULAKOWSKA, A., DYJA, H. Analysis of the rolling process of alloy 6005 in a three-high skew rolling mill. Materials. 2020, vol. 13, №1114.

[6] LENARD, J.G. Metal Forming Science and Practice. Elsevier Science, 2002. 